American J. of Engineering and Applied Sciences 2 (1): 1-7, 2009

ISSN 1941-7020

(C) 2009 Science Publications

\title{
Production of Pure Ethanol from Azeotropic Solution by Pressure Swing Adsorption
}

\author{
${ }^{1} \mathrm{P}$. Pruksathorn and ${ }^{1,2} \mathrm{~T}$. Vitidsant \\ ${ }^{1}$ Department of Chemical Technology, Faculty of Science, \\ Chulalongkorn University, Phayai Rd, Patumwan, Bangkok, 10330, Thailand \\ ${ }^{2}$ National Center of Excellence for Petroleum, Petrochemicals and Advanced Materials (NCE-PPAM), \\ Chulalongkorn University, Bangkok, 10330, Thailand
}

\begin{abstract}
There has been a gaining interest in the use of fuel ethanol from fermentation process. A main challenge in producing the ethanol concerned the production cost which was largely contributed by the process of water removal. Distillation could remove water to a certain level but due to ethanolwater azeotrope an extra process was needed before ethanol could be blended with gasoline. Problem statement: Pressure Swing Adsorption (PSA) process was attractive for final separation since it required less energy and lower setup cost. Despite many researches on simulation and experimental works on adsorption of water on 3A zeolite in a fixed bed, none have studied a process with the actual PSA system. Approach: The purpose of this research was to study the PSA process with two adsorbers and effects of several parameters. The research also included analysis of kinetic and thermodynamic data of ethanol-water adsorption on commercial $3 \mathrm{~A}$ zeolites in a single fixed bed. Two-level factorial design experiment was used in this research works to preliminary screen the influence and interaction among each factor. Results: From the experimental works, it was found that the most suitable condition for water adsorption on $30 \mathrm{~g}$ of zeolite was at $90^{\circ} \mathrm{C}$ initial bed temperature, feed flow rate of $1 \mathrm{~mL} \mathrm{~min}^{-1}$ and feed concentration of $95 \%$ vol ethanol. Langmuir isotherm could best predict the experimental results and the corresponding equation was proposed. In the PSA pilot test, the principal factors, which had an effect on the adsorption rate, recovery, and the enrichment of the product, were feed rate, feed concentration, adsorption pressure and the cycle time. Prediction of the process efficiency in terms of ethanol recovery and enrichment was proposed in the form of regression models. Conclusions/Recommendations: The results of the study in a fixed bed adsorber could help designing a pilot scale PSA unit. The experiments proved to be successful in terms of producing high concentration ethanol with acceptable percentage of ethanol recovery. With further simulation works, the process could be scaled up for an industrial use.
\end{abstract}

Key words: PSA, adsorption, separation, 3A zeolites

\section{INTRODUCTION}

Conventionally, azeotropic distillation has been employed in production of fuel-ethanol. In azeotropic distillation, dehydration is carried out in presence of entrainer like benzene or cyclohexane. Although benzene has been banned in several countries for its carcinogenic effect, cyclohexane is still being employed. Moreover, this distillation method is very energy intensive.

To bring down energy consumption and to ensure high level of dryness in final ethanol product, zeolite has proved to be ideal. There have been several researches on adsorption of water from ethanol/water mixture which can be categorized into two types of researches that include numerical simulation of dehydration of ethanol and water mixture ${ }^{[1-4]}$ and experimental works to study the effects of its operating parameters in a single column packed bed of $3 \mathrm{~A}$ zeolite $^{[5-7]}$. The effects of feed flow rate, feed concentration, adsorption temperature and adsorption pressure are among the interesting factors that are examined. Through these studies, it is suggested that dehydration by adsorption on $3 \mathrm{~A}$ zeolite has the advantage that the micropores are too small to be penetrated by alcohol molecules so that water is adsorbed without competition in the liquid phase. It requires little energy input and operates on cycles of short duration. Therefore, it has high adsorbent

Corresponding Author: Tharapong Vitidsant, National Center of Excellence for Petroleum, Petrochemicals and Advanced Materials (NCE-PPAM), Chulalongkorn University, Phayai Rd, Patumwan, Bangkok, 10330, Thailand Tel: +66 2218 7523-5 Fax: +66 22555831 
productivity and is often capable of producing very pure product. Despite many literatures which studied on adsorption of water on $3 \mathrm{~A}$ zeolite through simulations and experimental works, there has been no real effort on the investigation of its productivity and performance on actual PSA system. This research aims to study the actual effects of different operating parameters on the efficiency of PSA system mainly in terms of product recovery and enrichment.

\section{MATERIALS AND METHORDS}

This research focuses on water separation from ethanol-water solution under vapor phase with the use of $3 \mathrm{~A}$ zeolite. The first phase testing was done in a fixed-bed adsorber under atmospheric pressure to study the optimum condition for adsorption and to compare the performance under difference operating conditions. The zeolite was packed in a stainless steel column with inner diameter of $1.59 \mathrm{~cm}$ and the length of $45 \mathrm{~cm}$ placing in a tube furnace to maintain the temperature at desired values (Fig. 1). Carberry ${ }^{[8]}$ suggested a tube to particle ration of less than 5-6 to avoid excessive radial temperature gradient, hence the ratio of 3.2-6.4 was used. Low concentration ethanol/water mixture was evaporated and fed through the packed bed from the top. This avoided fluidization of the zeolite at higher feed rate. Once the adsorption column was saturated, the zeolite was removed and regenerated by heating in an oven at $220^{\circ} \mathrm{C}$. Prior to each run the regenerated zeolite was re-packed into the column and put under $300^{\circ} \mathrm{C}$ with nitrogen gas flow through. The experiments studied the adsorption of water on $3 \mathrm{~A}$ zeolite at a flow rate of $1-2 \mathrm{~mL} \mathrm{~min}^{-1}$,

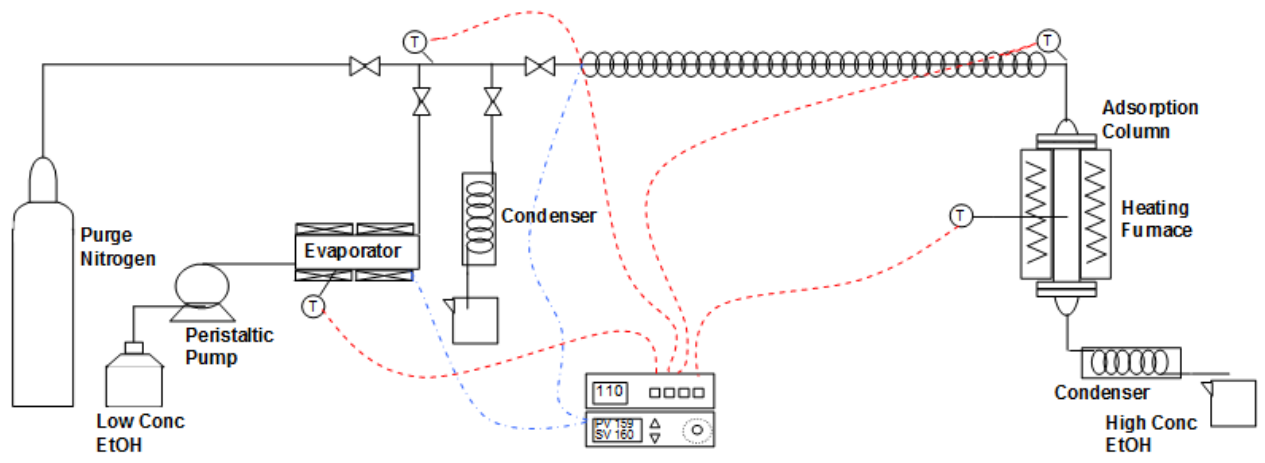

Fig. 1: Process flow diagram of the fixed bed adsorption column

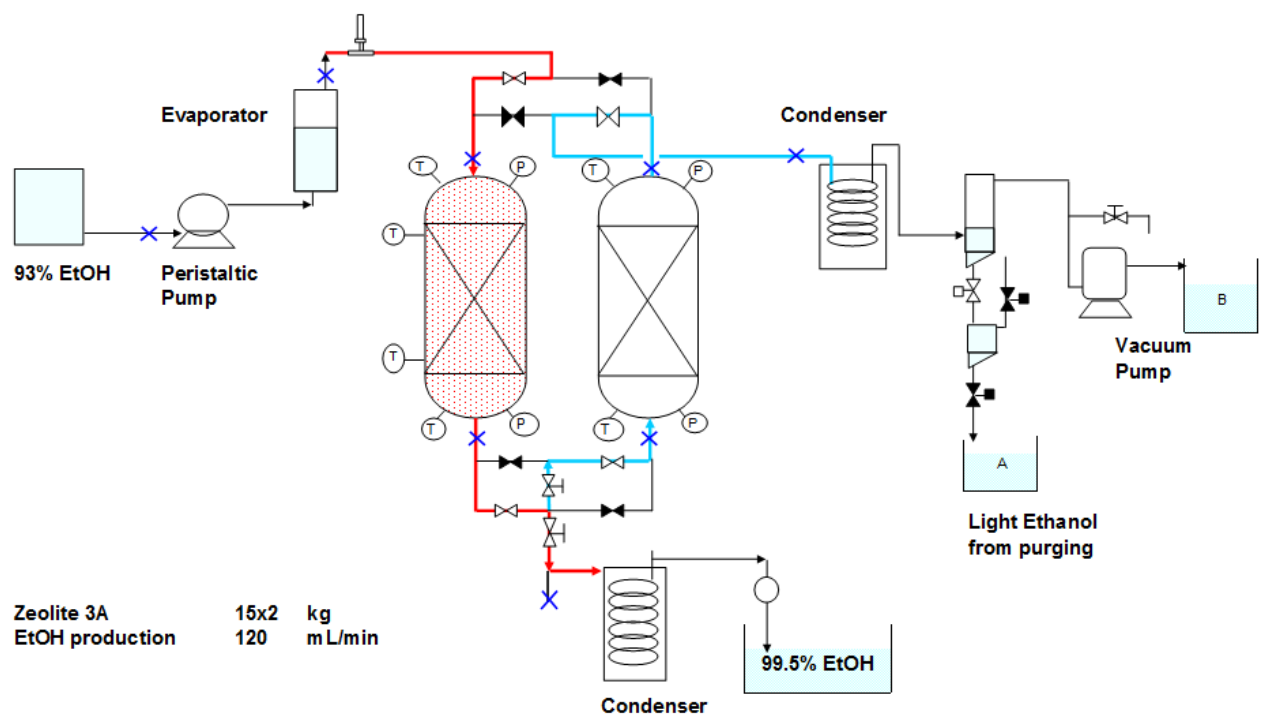

Fig. 2: Process flow diagram of the PSA pilot plant 
Am. J. Engg. \& Applied Sci., 2 (1): 1-7, 2009

Table 1: Phase one testing. Adsorption of water on $30 \mathrm{~g}$ of $3 \mathrm{~A}$ molecular sieve

\begin{tabular}{|c|c|c|c|c|c|c|c|c|c|}
\hline \multicolumn{6}{|c|}{$3 \mathrm{~A}$} & \multicolumn{2}{|c|}{ Theoretical } & \multicolumn{2}{|c|}{ Experimental } \\
\hline Run No. & $\mathrm{T}\left({ }^{\circ} \mathrm{C}\right)$ & 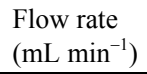 & $\begin{array}{l}\text { Conc } \\
(\% \mathrm{v} \text { EtOH })\end{array}$ & $\begin{array}{l}\text { Breakthrough } \\
\text { time }(\mathrm{sec})\end{array}$ & $\begin{array}{l}\text { Q, } \\
\text { (g.H2O/g.abs) }\end{array}$ & $\begin{array}{l}\text { LES } \\
(\mathrm{cm})\end{array}$ & $\begin{array}{l}\text { LUB } \\
(\mathrm{cm})\end{array}$ & $\begin{array}{l}\text { LES } \\
(\mathrm{cm})\end{array}$ & $\begin{array}{l}\text { LUB } \\
(\mathrm{cm})\end{array}$ \\
\hline 1 & 100 & 1 & 95 & 3400 & 0.123 & 14.74 & 9.26 & 14.57 & 9.43 \\
\hline 2 & 100 & 2 & 95 & 850 & 0.104 & 8.55 & 15.45 & 8.77 & 15.23 \\
\hline 3 & 100 & 1 & 90 & 1950 & 0.163 & 12.91 & 11.09 & 11.77 & 12.23 \\
\hline 4 & 100 & 2 & 90 & 540 & 0.135 & 8.54 & 15.46 & 6.86 & 17.14 \\
\hline 5 & 120 & 1 & 95 & 2800 & 0.097 & 15.14 & 8.86 & 15.27 & 8.73 \\
\hline 6 & 120 & 2 & 95 & 800 & 0.087 & 9.60 & 14.40 & 9.37 & 14.63 \\
\hline 7 & 120 & 1 & 90 & 1800 & 0.148 & 13.02 & 10.98 & 11.08 & 12.92 \\
\hline 8 & 120 & 2 & 90 & 480 & 0.127 & 8.09 & 15.91 & 6.40 & 17.60 \\
\hline
\end{tabular}

temperature of 100 and $120^{\circ} \mathrm{C}$ and the concentration between 85 and $95 \% \mathrm{v} / \mathrm{v}$.

In the second phase of the study, the pilot modeling of the cyclic PSA process was then designed along with its control system (Fig. 2) based on the results found in the first phase. Operating conditions were similar to the industrial process. Normally, two or three beds PSA arrangements are used in the industry; in this study the two beds cycle was considered. The half cycle of ethanol PSA process, sequence of the operation and interactions between beds were also designed. The PSA cycle can be divided into two stages which were adsorption or production stage and desorption stage. During adsorption the water-ethanol vapor stream was fed to the bed from the top under high pressure. The product stream was collected at the bottom of the bed. Part of the product stream was used to re-pressurize and purge the bed during the desorption stage. The adsorption stage took about 600-900 seconds. Desorption stage followed after the production stage was completed. The bed must then be depressurized, regenerated and re-pressurized to the adsorption pressure. All these steps are controlled by closing/opening of controlled valves through the use of PLC system.

Zeolite type $3 \mathrm{~A}$ was used as adsorbent in the form of spheres with nominal diameter of $2.5-5 \mathrm{~mm}$, as obtained from Zeochem ${ }^{\circledR}$ molecular sieve Z3-03. The bed was also characterized by determining some of its physical properties, which included the calculation of the porosity of the bed. A stainless steel vessel was used (50 cm in length; $20 \mathrm{~cm}$ i.d.). Its dimensions ensured good flow distribution since the bed internal diameter was at least 10 times as much as the particle size and its length was at least 100 times as much as the particle size ${ }^{[9]}$. Each column was packed with $15 \mathrm{~kg}$ of 3 A zeolite.

The ethanol-water solution was prepared from anhydrous ethanol and distilled water at concentrations of $92-95 \%$ vol ethanol. In order to measure the concentration of the fluid phase, an Anton Paar Density/Specific Gravity/Concentration meter was used and data repeatability of $0.5 \%$ was obtained with the accuracy of $\pm 0.001 \mathrm{~g} \mathrm{~cm}^{-3}$. The experimental setup was divided into four main parts: feed system (composed of a 20-liter tank, peristaltic pump, evaporator, valves, pipes and connections), central body (composed of two adsorption columns, heating system, valves, pipes and vacuum pump), a product collection system (composed of collectors, two tube heat exchangers and a cooling bath) and a control system with data collection and user interface units.

All experiments were organized by a $2 \mathrm{~K}$ factorial design which allowed fitting of models from a reduced number of experimental points, accomplishing interactions among the variables and the linear terms of each variable. The experiments investigated the effect of different operating parameters such as feed rate (80$\left.100 \mathrm{~mL} \mathrm{~min}^{-1}\right)$, feed concentration $(92-95 \%$ vol ethanol), adsorption pressure (2-2.4 Bar A) and cycle time (10-15 mins). The univariate experiment was then used to investigate the influence of each factor on the performance of the PSA system.

\section{RESULTS}

First phase-fixed bed adsorber: The main purpose of this part of the experiment was to show the effects of flow rate, temperature and feed concentration on breakthrough time and water capacity. From Table 1, it can be seen that at $100^{\circ} \mathrm{C}$, flow rate of $1 \mathrm{~mL} \mathrm{~min}^{-1}$ and feed concentration of $95 \%$ vol gave the longest breakthrough time at 3400 seconds. When compared at the same flow rate and feed concentration, lower initial temperature yielded higher breakthrough time and water adsorption capacity. In addition, the table shows that at, in most cases, performing the adsorption process at higher flow rates or lower ethanol concentration can reduce the length of equilibrium zone (LES) and hence longer Length of Unused Bed (LUB).

Fig. 3 shows the amount of water that was adsorbed by different packing zeolite weights at a flow 
Am. J. Engg. \& Applied Sci., 2 (1): 1-7, 2009

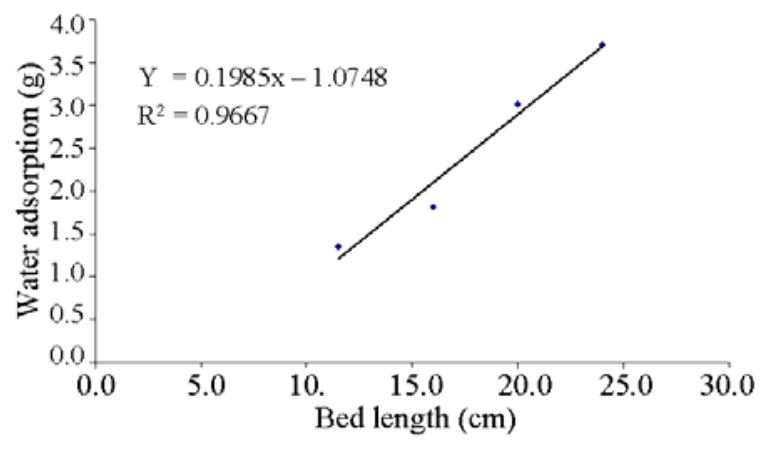

Fig. 3: Relationship between water capacity and bed length

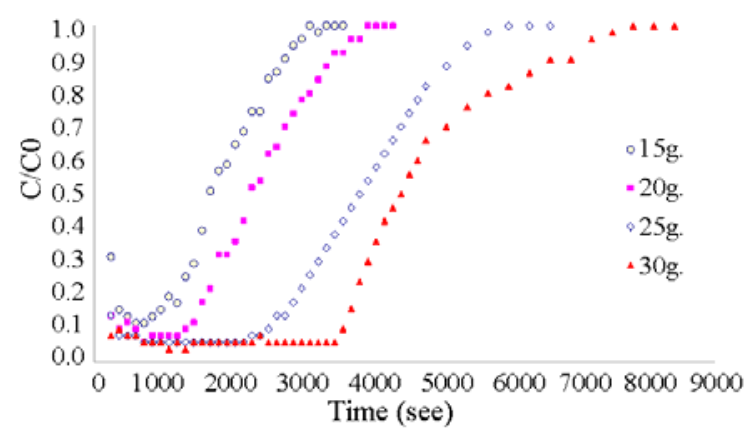

Fig. 4: Breakthrough time of difference packing weight

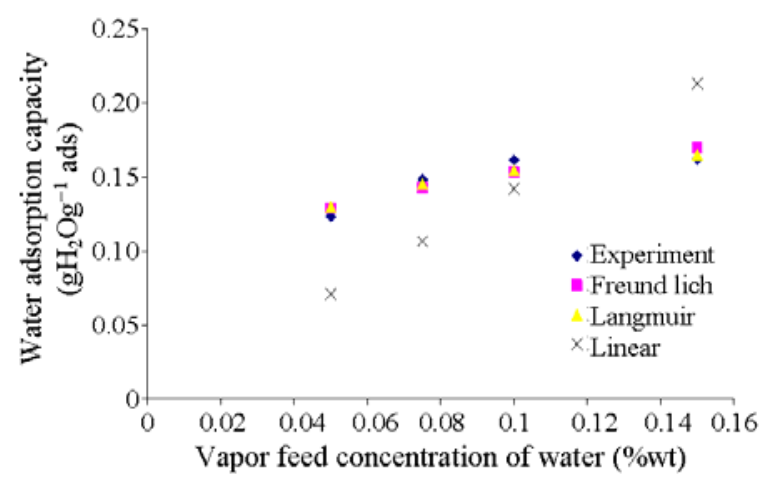

Fig. 5: Fitting of experimental data with various adsorption isotherms

rate of $1 \mathrm{~mL} \mathrm{~min}^{-1}, 100^{\circ} \mathrm{C}$ and feed concentration of $95 \%$ vol. It can be seen that, in case of a same operating condition, water adsorption capacity is a direct proportion of the loading of the zeolite in the adsorber. Likewise, Fig. 4 shows that breakthrough time is highly dependable on the weight of the zeolite, given a particular adsorption condition. In this case the longest
Table 2: PSA experimental conditions and results

\begin{tabular}{lllllll}
\hline & $\begin{array}{l}\text { Feed rate } \\
\left(\mathrm{mL} \mathrm{min}^{-1}\right)\end{array}$ & $\begin{array}{l}\text { Feed } \\
\text { conc } \\
(\% \text { vol })\end{array}$ & $\begin{array}{l}\text { Adsorption } \\
\text { pressure } \\
(\text { Bar })\end{array}$ & $\begin{array}{l}\text { Cycle } \\
\text { time } \\
(\mathrm{min})\end{array}$ & $\begin{array}{l}\text { Recovery } \\
(\%)\end{array}$ & $\begin{array}{l}\text { Product } \\
\text { conc } \\
(\% \text { vol })\end{array}$ \\
\hline 1 & 100 & 92 & 2.0 & 10 & 82.01 & 99.64 \\
2 & 100 & 92 & 2.4 & 10 & 84.90 & 99.56 \\
3 & 80 & 92 & 2.4 & 10 & 80.78 & 99.61 \\
4 & 100 & 92 & 2.4 & 15 & 85.26 & 99.66 \\
5 & 100 & 95 & 2.0 & 15 & 76.63 & 99.50 \\
6 & 100 & 95 & 2.4 & 15 & 74.88 & 99.54 \\
7 & 100 & 95 & 2.0 & 10 & 70.54 & 99.58 \\
8 & 80 & 95 & 2.4 & 15 & 84.28 & 99.58 \\
9 & 100 & 92 & 2.0 & 15 & 84.46 & 99.64 \\
10 & 80 & 95 & 2.0 & 10 & 76.91 & 99.59 \\
11 & 80 & 92 & 2.4 & 15 & 82.67 & 99.52 \\
12 & 80 & 92 & 2.0 & 15 & 81.91 & 99.64 \\
13 & 80 & 95 & 2.4 & 10 & 73.58 & 99.53 \\
14 & 80 & 92 & 2.0 & 10 & 78.24 & 99.56 \\
15 & 100 & 95 & 2.4 & 10 & 74.68 & 99.57 \\
16 & 80 & 95 & 2.0 & 15 & 82.32 & 99.60 \\
\hline
\end{tabular}

breakthrough time of 3600 seconds was achieved when $30 \mathrm{~g}$ of zeolite was used.

Fig. 5 shows fittings of experimental results with different adsorption isotherms. In this case Langmuir isotherms could best predict the adsorption capacity of the $3 \mathrm{~A}$ zeolite.

Second phase-PSA pilot plant: After some characterization and kinetics study of the $3 \mathrm{~A}$ zeolite were completed, the PSA pilot plant was designed on the assumption of the predicted isotherm and the isotherm data from the commercial grade zeolite used in this research. Factors that were taken into considerations were flow rate, feed concentration, adsorption pressure and cycle time for each adsorption stage. Table 2 For each of the experimental run, the pilot plant was run until it reached steady state $e^{[11]}$ and was run repeatedly as a cyclic batch operation.

From analysis of variance (ANOVA) using Design-Expert software package (Fig. 7), it was proven that cycle time, feed concentration and the interaction between feed concentration and feed rate significantly affected the performance of the PSA pilot plant in term of ethanol recovery. On the other hand, the product concentration was largely depending on feed concentration, adsorption pressure and some interactions between different variables. It must also noted that during adsorption and regeneration the temperature increased and decreased in the range of 10$15^{\circ} \mathrm{C}$ due to heat of adsorption and heat used to evaporate water during desorption, respectively ${ }^{[12,13]}$. The PSA unit attempted to maintain the temperature by slightly adapting the feed temperature so that it would leverage with heat released or consumed during adsorption or desorption, respectively. 

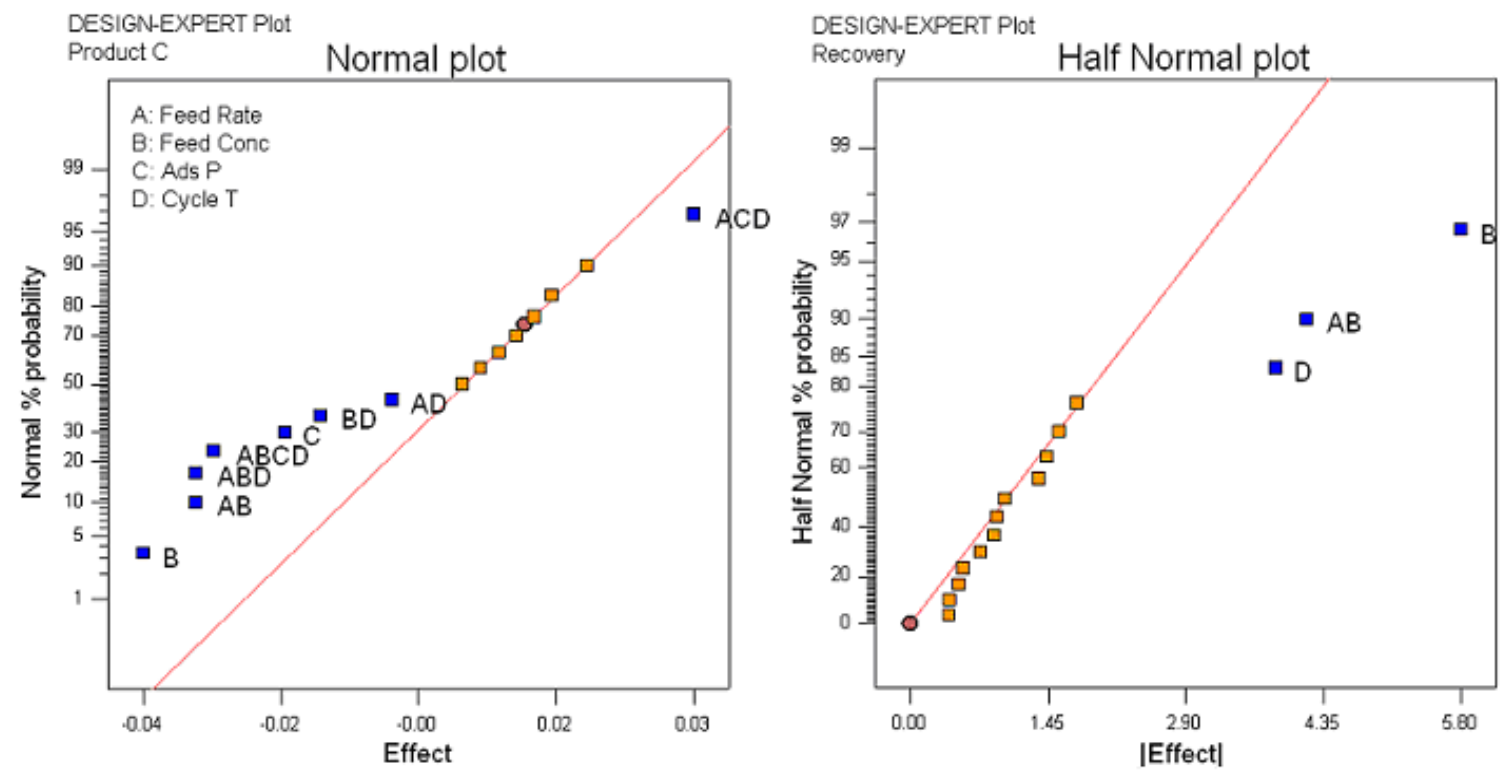

Fig. 7: Design-Expert plots showing significant effects on production concentration and ethanol

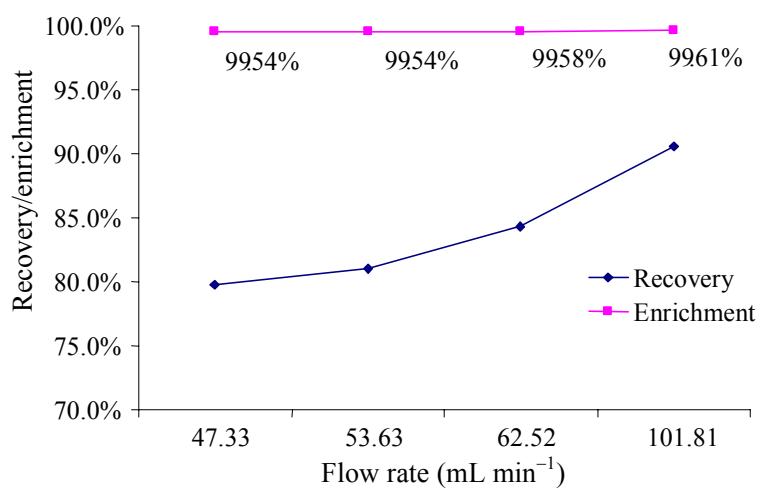

Fig. 8: Effect of flow rate on product concentraion and ethanol recovery

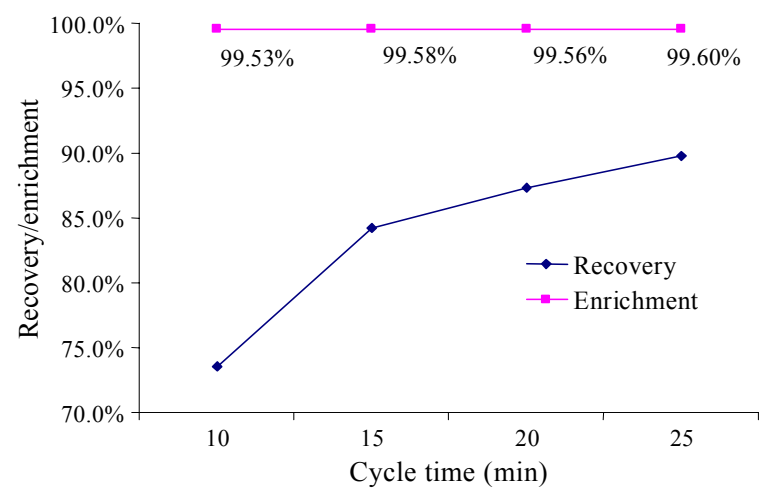

Fig. 9: Effect of cycle time on product concentraion and ethanol recovery
Equation 2 and 3 show regression models used to predict the performances of the PSA pilot plant. From Equation 2, recovery of ethanol can be increased by reducing feed concentration, increasing cycle time and reducing feed rate. However, in the case of the concentration of the ethanol product, further study is needed to better explain the effects of each factor

Recovery $=79.63-2.90 \mathrm{~B}+1.92 \mathrm{D}-2.09 \mathrm{AB}$

Product $\mathrm{C}=99.58-0.021 \mathrm{~B}-0.011 \mathrm{C}-0.017 \mathrm{AB}$

$-0.017 \mathrm{ABD}+0.017 \mathrm{ACD}-0.016 \mathrm{ABCD}$

From Eq. 2 and 3, further experiments were done to study the effect of flow rate on production concentration and ethanolrecovery. Fig. 8 shows the effect of flow rate on product concentration and ethanol recovery. It can be seen that increasing the flow rate would significantly improve ethanol recovery. Furthermore, it shows that a slight increase in ethanol concentration can be expected as the flow rate increased.

The experiment was further conducted to investigate the effect of cycle time for each adsorption step. From Fig. 9, it can be seen that an increase in cycle time from 10 to $25 \mathrm{~min}$ can improve the percentage of the ethanol recovery from $73.58 \%$ to $89.72 \%$. However, the ethanol concentration of the product seems to be less dependent on the cycle time. 


\section{DISCUSSION}

The experiment was divided into two parts. The first part was carried out mainly to study the adsorption isotherms of the system and to see how it was affected by different operating parameters. From Table 1, when compared at the same flow rate and feed concentration, lower initial temperature yielded higher breakthrough time and water adsorption capacity. This could be explained by the fact that adsorption is exothermic reaction hence it works better at lower temperature.

When adsorption process took place at the same temperature and same water concentration, higher flow rate resulted in shorter breakthrough time and lower water adsorption capacity. Higher feed rate meant higher vapor velocity and consequently resulted in a shorter contact time. Furthermore, by increasing the flow rate, the zeolite was exposed to more amount of water per unit of time. However, higher flow rate resulted in higher vapor velocity and lower film resistance and as a consequent reduced LES. As adsorption took place at same temperature and same flow rate, higher ethanol feed concentration resulted in a longer breakthrough time because there was less amount of water. But when the ethanol feed concentration was lower, the breakthrough time occurred in a shorter period of time. Again the main reason for earlier breakthrough times with increasing water concentration is that the adsorbent is exposed to more adsorbate per unit time ${ }^{[10]}$. However, at same conditions, lower ethanol feed concentration led to higher water adsorption capacity and shorter LES. Since lower ethanol concentration had higher amount of water and, hence the adsorption took place at higher water partial pressure. As a result, higher adsorption rate could be expected.

The experimental data also showed that the adsorption could be precisely predicted by Langmuir Isotherm. As a result, monolayer adsorption of water from ethanol/water mixture on $3 \mathrm{~A}$ zeolite can be expected.

The second part of the experiment was done in a pilot-scale PSA system which was designed based on some of the information derived from the first part.

It can be seen in from the experimental results that increasing flow rate and cycle time could significantly increase the percentage of ethanol recovery. After every given cycle time the adsorber needs to be regenerated. Certain amount of ethanol that is left in the voidage and dried ethanol that is used as purge stream are taken out during regeneration. As a result, the higher the amount of ethanol being fed during adsorption process, the higher the percentage of the ethanol recovery of the PSA system. Likewise, the shorter the cycle time, the more amount of dried ethanol as purge stream is needed during regeneration.

However, the effect of the cycle time on the product concentration cannot be clearly seen since the amount of zeolite packed in the adsorber was in abundant and the breakthrough had not yet occurred. It can be suggested that increasing adsorption pressure to increase the water partial pressure and hence increasing the adsorption capacity can improve the quality of the product or the ethanol concentration. Furthermore, it was shown in Fig. 8 that as the flow rate is increased, the ethanol product concentration was also higher. This could be explained by the fact that adsorption rate is higher when the vapor is fed at higher velocity which would drastically reduce the film resistance.

\section{CONCLUSION}

In this research, the process of ethanol-water separation in the PSA process was studied. The research included analysis of kinetic and thermodynamic data of ethanol-water adsorption on commercial 3A zeolites. The first phase of the testing was done in a fixed-bed adsorber under atmospheric pressure to study the optimum condition for adsorption. The experiment showed that increasing initial temperature of the bed would reduce water capacity of the zeolite and that breakthrough time was decreased as ethanol-water solution feed flow rate was increased. Additionally, it can be suggested that the lower concentration of the feed solution, the sooner the bed saturated. From the study, it was found that the most suitable condition for water adsorption on $30 \mathrm{~g}$ of zeolite was at $90^{\circ} \mathrm{C}$ initial bed temperature, feed flow rate of $1 \mathrm{~mL} \mathrm{~min}{ }^{-1}$ and feed concentration of $95 \%$ vol ethanol. Finally it was found that, Langmuir isotherm could best predict the experimental results with the corresponding equation of $\mathrm{q}=\left(8.18^{\circ} \mathrm{C}\right) /\left(1+42.83^{\circ} \mathrm{C}\right)$.

It was also shown that by increasing the feed flow rate in a PSA process the quality of the product (enrichment of ethanol) increased marginally. At the same time, increased flow rate provided a significant increase in its recovery and productivity. On the other hand, increasing pressure leads to an improvement in the enrichment but decreases the recovery and productivity. Furthermore, it is found that, for similar adsorption and desorption conditions, shorter cycle within each operation gave a constant high-quality product but at a lower quantity. It was also proven that the designed PSA system was able to continuously produce high concentration ethanol product. Two regression models were found in the effort to predict 
the quality of ethanol product and the PSA system performance in term of ethanol recovery. Further work could involve a simulation of the PSA pilot plant in the purpose of scaling up the system to be used in the industrial scale.

\section{ACKNOWLEDGEMENT}

The researchers would like to express our gratitude to the National Center of Excellence for Petrroleum, Petrochemicals and Advanced Materials (NCE-PPAM) and Department of Chemical Technology Chulalongkorn University. The thankfulness should be extended to Sutech Engineering Co., Ltd. for the testing equipments.

\section{REFERENCES}

1. Guan, J. and X. Hu, 2003. Simulation and analysis of pressure swing adsorption: Ethanol drying process by the electrical analogue. Separat. Purificat. Technol., 31: 31-35. DOI: 10.1016/S1383-5866(02)00151-X

2. Jain, S., A.S. Moharir, P. Lo and G. Wozny, 2003. Heuristic design of pressure swing adsorption: A preliminary study. Separat. Purificat. Technol., 33: 25-43. DOI: 10.1016/S1383-5866(02)00208-3

3. Ahn, H. and S. Brandani, 2005. A new numerical method for accurate simulation of fast cyclic adsorption processes. Adsorption, 11: 113-122. DOI: $10.1007 / \mathrm{s} 10450-005-4902-2$

4. Simo, M., C.J. Brown and V. Hlavacek, 2008. Simulation of pressure swing adsorption in fuel ethanol production process. Comput. Chem. Eng., 32: 1635-1349. DOI: 10.1016/j.compchemeng.2007.07.011

5. Carmo, M.J. and J.C. Gubulin, 2002. Ethanol-water separation in the PSA process. Adsorption, 8: 235-248. DOI: 10.1023/A:1021264601910
6. Pozas, C., R.L. Cordero, J.A. Morales, N. Travieso and R.R. Malherbe, 1993. Effect of pore diameter and acid strength in ethanol dehydration on molecular sieves. J. Mol. Catal., 83: 145-156. DOI:10.1016/0304-5102(93)87015-Z

7. Teo, W.K. and D.M. Ruthven, 1986. Adsorption of water from aqueous ethanol using $3 \mathrm{~A}$ molecular sieves. Ind. Eng. Chem., 25: 17-21. DOI: 10.1021/i200032a003

8. Carberry, J.J. and Varma, A., 1976. Chemical and Catalytic Reaction Engineering. 1st Edn., McGraw-Hill, New York, USA, pp: 530-535.

9. Madson, P.W. and D.A. Monceaux, 1994. The Alcohol Textbook: Fuel Ethanol Production. 3rd Edn., Nottingham University Press, Nottingham, United Kingdom, pp: 257-268.

10. Sowerby, B. and B.D. Crittenden, 1988. An experimental comparison of type A molecular sieves for drying the ethanol-water azeotrope. Gas Separat. Purificat., 2: 77-83. DOI: 10.1016/09504214(88)80016-1

11. Kvarmsdal, H.M. and T. Hertzberg, 1997. Optimization of Pressure Swing Adsorption (PSA) systems-studies on cyclic steady state convergence. Comput. Chem. Eng., 21: 819-832. DOI:10.1016/S0098-1354(96)00315-8

12. Lalik, E., R. Mirek, J. Rakorczy and A. Groszek, 2006. Microcalorimetric study of sorption of water and ethanol in zeolites $3 \mathrm{~A}$ and $5 \mathrm{~A}$. Catal. Today, 114: 242-247. DOI: 10.1016/j.cattod.2006.01.006

13. Salem, M. and B. Shebil, 1999. Effect of heat of adsorption on the adsorptive drying of solvents at equilibrium in a packed bed of zeolite. Chem. Eng. J., 74: 197-204. DOI:10.1016/S13858947(99)00027-3. 